\title{
ANÁLISE DO IMPACTO DOS REPASSES ESTADUAIS E FEDERAIS NO DESENVOLVIMENTO DOS MUNICÍPIOS DE SANTA CATARINA
}

\author{
ANALYSIS OF IMPACT OF FEDERAL AND STATE \\ GOVERNMENTS TRANSFERS IN DEVELOPMENT OF THE \\ MUNICIPALITIES IN THE OF SANTA CATARINA
}

\author{
Data de submissão: 05/12/2013 \\ Aceite: 20/05/2016 \\ Júlio César Silva ${ }^{1}$ \\ Rosemar José Hall ${ }^{2}$ \\ Itzhak David Simão Kaveski ${ }^{3}$ \\ Nelson Hein ${ }^{4}$
}

\section{RESUMO}

O objetivo desta pesquisa é analisar a relação entre os repasses de recursos estaduais e federais no desenvolvimento dos municípios de Santa Catarina. A pesquisa foi classificada como descritiva, com procedimentos que a caracterizam como documental, com dados dos repasses de recursos estaduais (ICMS) e Federais (FUNDEB e FPM) recebidos pelos 293 municípios do estado de Santa Catarina no período de 2008 a 2011. Quanto à abordagem, a pesquisa foi caracterizada como quantitativa, com a utilização da regressão linear múltipla. Os principais resultados da pesquisa demonstram haver uma relação entre o desenvolvimento dos municípios e a captação de recursos. E, também demonstrou que o fato de ter um valor maior de recursos implica em ter um IFDM maior. Vários municípios com grandes entradas de recursos apresentaram um valor de IFDM (2012) menor que sua posição no ranking de arrecadação, contudo nos cenários projetados para 2013 e 2014 as posições do ranking apresentam um viés de aumento, ou seja, começaram a melhorar.

Palavras-chave: Repasses estaduais e federais; Gestão pública, Desenvolvimento dos municípios.

\footnotetext{
1 Possui doutorado em Ciências Contábeis e Administração pela Universidade de Blumenau - FURB (2015). Mestre em Engenharia de Produção pela Universidade Federal de Santa Catarina - UFSC (2003) e Graduado em Administração pela Fundação Educacional Regional Jaraguaense -FERJ (1997). É Professor de Graduação e Pós-Graduação em nível de Especialização. Foi professor visitante do Instituto Tecnológico y de Estudios Superiores de Monterrey-México e professor de Pós-Graduação da École des Mines - Saint Etienne- France Intituto Heliopolis e UNERJ.Blumenau. Santa Catarina. Brasil. E-mail: profjuliosilva72@gmail.com

2 Possui graduação em Ciências Contábeis pela Universidade Federal do Estado do Mato Grosso Do Sul, UFMS, especialização em Metodologia do Ensino Superior pelo Centro Universitário da Grande Dourados, UNIGRAN, especialização em Administração Financeira pela Universidade Federal do Estado do Mato Grosso do Sul, UFMS, especialização em Gestão da Clínica nos Hospitais do SUS pelo Hospital Sírio-Libanês, mestrado em Agronegócios pela Universidade Federal de Mato Grosso do Sul, UFMS e doutorado em Ciências Contábeis pela Fundação Universidade Regional de Blumenau, FURB. Atualmente é professor da Universidade Federal da Grande Dourados. Dourados. Mato Grosso do Sul. Brasil. E-mail: RosemarHall@ufgd.edu.br 3 Possui graduação em Ciências Contábeis pela Universidade Estadual de Mato Grosso do Sul, UEMS, mestrado em Ciências Contábeis pela Fundação Universidade Regional de Blumenau, FURB e doutorado em andamento em Contabilidade pela Universidade Federal de Santa Catarina, UFSC. Atualmente é professor assistente A1 do Campus do Pantanal da Universidade Federal de Mato Grosso do Sul. E-mail: itzhak.konoha@gmail.com 4 Possui graduação em Ciências de I Grau, graduação em Matemática e especialização em ensino de ciências/matemática pela Universidade Regional de Blumenau, FURB, mestrado e doutorado em Engenharia de Produção pela Universidade Federal de Santa Catarina, UFSC. Blumenau. Santa Catarina. Brasil. E-mail: hein@furb.br
} 


\begin{abstract}
The objective of this research is to analyze the relationship between the transfers of state and federal resources on developing the municipalities of Santa Catarina. The research was classified as descriptive, with procedures that characterize it as a documentary, with data from the state fund transfers (ICMS) and federal (FUNDEB and FPM) received by the 293 municipalities of Santa Catarina from 2008 to 2011. As for approa$c h$, the research was characterized as quantitative, using multiple linear regression. The main results of the research demonstrate a relationship between the development of municipalities and fundraising. And, also demonstrated that the fact that a greater amount of resources implies having a greater IFDM. Several municipalities with large resource inputs had a value of IFDM (2012) lower than its position in revenue ranking, however the scenarios projected for 2013 and 2014 the ranking positions have an increased bias, which is, began to improve.
\end{abstract}

Keywords: State and federal transfers; Public administration; Municipal development.

\title{
1 INTRODUÇÃO
}

A economia brasileira, até recentemente, conquistava ganhos significativos em comparação aos países considerados de economias desenvolvidas, como EUA e Europa, porém, a crise econômica mundial afetou o Brasil e no ano de 2015 os números não são favoráveis, de acordo com Máximo (2015) o Governo Federal Prevê uma queda na arrecadação em torno de R\$ 7 bilhões, devido à redução da produção da industrial, e à redução do lucro das empresas (MÁXIMO, 2015).

Em direção contrária da crise o Estado de Santa Catarina prevê aumento de arrecadação para 2015, na ordem de 10,5\% superior a 2014 (SANTA CATARINA, 2015). O que apresenta uma continuidade na evolução de arrecadação, o Estado de Santa Catarina no ano de 2011 teve um crescimento na sua arrecadação na ordem de 15,84\%, estes resultados estão diretamente ligados com o próprio aumento arrecadatório, mas não somente, deve-se somar o gerenciamento de política de austeridade dos gastos públicos (SANTA CATARINA, 2011). Em 2012 a arrecadação só do ICMS, para o estado de Santa Catarina foi, em torno de 12 bilhões, em para 2013 aumentou para próximo de 14,1 Bilhões (FIESC, 2014).

As regiões Sul e Sudeste, por serem mais desenvolvidas economicamente, conseguem maior arrecadação de ICMS e, portanto, maior capacidade de obtenção de recursos refletindo na meIhor provisão de bens públicos para suas comunidades (TORRES, 2013). Em contrapartida é necessária uma gestão pública eficiente, que beneficie os cidadãos. Em 2011 os investimentos realizados, por Santa Catarina, nas áreas consideradas sociais atingiram a marca de R\$ 916 milhões, com investimentos prioritários em transporte e urbanismo, educação, segurança pública, saúde, habitação, agricultura, dentre outros, e neste valor não estão incluídos os repasses constitucionais (SANTA CATARINA, 2011). Devido ao processo de afunilamento de ações e consequências, são os municípios os meios mais rápidos e diretos de alcance ao cidadão e contribuinte, pelas ações governamentais.

Na concepção de Zmitrowicz, Biscaro e Marins (2013) o desempenho da gestão dos municípios tem sido prejudicado pelo crescimento e desenvolvimento urbano desenfreado. Conforme os autores, este desenvolvimento ocasiona a necessidade premente de gestões públicas adequadas, eficientes e presentes com os anseios de sua comunidade, com uma necessidade de maiores recursos a sua disposição, e com processos gerenciais mais aprimorados. Invariavelmente o que acontece nos 293 municípios do estado de Santa Catarina também ocorre em outros municípios do Brasil, ou seja, "pelo princípio federativo o produto da arrecadação tributária é repartido entre as esferas de governo e essa repartição é denominada transferência intergovernamental e está estabelecida constitucionalmente" (MORATTA, 2015, P. 63). Dessa forma os 
impostos, são recolhidos localmente nos municípios, transferidos para o estado e união e retornando posteriormente por meio da transferência intragovernamental.

Diante do impasse sobre o que se recebe de recursos e suas consequências nos municípios faz surgir a seguinte questão de pesquisa: Qual a relação dos repasses de recurso no desenvolvimento dos municípios de Santa Catarina? Para a resolução da questão problema, foi estabelecido como objetivo de pesquisa, analisar a relação entre os repasses de recursos estaduais e federais no desenvolvimento dos municípios de Santa Catarina. Os recursos estaduais e federais utilizados na pesquisa foram o ICMS, FUNDEB e Fundo de Participações dos Municípios (FPM) que representam o montante de $95,93 \%$ do total repassado aos municípios na forma de retorno dos tributos, não computados nesta totalização os repasses indiretos através de programas e projetos sociais, de acordo com a FECAM (2012). Para medir o desenvolvimento dos municípios de Santa Catarina, utilizou-se o Índice Firjan de Desenvolvimento Municipal (IFDM), elaborado pela Federação das Indústrias do Estado do Rio de Janeiro (FIRJAN), como forma de monitorar os indicadores sociais. O IFDM concentra os resultados alcançados pela educação, trabalho e renda, dos municípios de todo o país (FIRJAN, 2013).

\section{REVISÃO DA LITERATURA}

Nesse item, são descritos a revisão da literatura que trata da gestão pública, transferências de recursos e estudos similares, desenvolvidos por outros pesquisadores.

\subsection{Gestão pública}

A administração pública é todo o aparato governamental organizado em pessoas e recursos, utilizados para a realização dos objetivos de um governo, em todas suas instâncias, municipal, estadual e federal, segundo Waldo $(1971$, p. 6), "organização é a gerência de homens e materiais para a consecução dos propósitos de um governo". Cabe ao governante direcionar os objetivos da administração à coletividade e ao cidadão, pois de acordo com Harmon e Mayer (1999), a administração pública é o trabalho de todos aqueles que atuam em nome do povo, em nome da sociedade, que delega de forma legal, e cujas ações têm consequências para os indivíduos e grupos sociais.

Para Meirelles (1984, p. 131) "o termo administração pública deve ser citado e. considerando que a mesma seja todo o aparelhamento do Estado, reordenado à realização de seus serviços, visando à satisfação das necessidades coletivas". Com o propósito de atingir as reais finalidades, a administração pública passou a ser compreendida e executada através de processos gerenciais, com indicadores e ênfase nos resultados. Conforme afirma Bresser-Pereira (2006, p.28):

A administração pública gerencial emergiu na segunda metade do século XX como resposta à crise do Estado, como modo de enfrentar a crise fiscal, como estratégia para reduzir o custo e tornar mais eficiente a administração dos imensos serviços que cabiam ao Estado e como um instrumento de proteção do patrimônio público contra os interesses do rent-seeking ou da corrupção aberta.

Segundo Matias-Pereira (2008) no Brasil, com a reforma realizada na década de 1990, estabeleceu-se a nomenclatura "administração pública gerencial", que deriva da expressão nova administração pública, no contexto do processo de reforma do aparelho estatal. "O Brasil buscou delinear um novo padrão de gestão pública, a denominada administração gerencial, apoiada nos princípios da flexibilidade, ênfase em resultados, foco no cliente e controle social" (MATIAS-PEREIRA, 2008 p. 75-76). 
A configuração dos modelos de gestão pública é influenciada pelo momento histórico e pela cultura política que caracterizaram uma determinada época do país. Assim, a evolução, o aperfeiçoamento e a transformação dos modelos de gestão das organizações se desenvolvem a partir das pressões políticas, sociais e econômicas existentes e que se traduzem em diferentes movimentos reformistas empreendidos pelos governos que buscam um alinhamento com as demandas sociais internas e externas (FIATES, 2007).

A Reforma da Gestão Pública ou reforma gerencial do Estado brasileiro teve início em 1995, após a publicação do Plano Diretor da Reforma do Estado e o envio da emenda da administração pública (Emenda 19) para o Congresso Nacional. Nos quatro primeiros anos do governo Fernando Henrique a reforma foi executada em nível federal, no Ministério da Administração Federal e Reforma do Estado (MARE). Após a extinção do MARE, a gestão passou para o Ministério do Planejamento e Gestão, e os estados e municípios passavam a fazer suas próprias reformas (BRESSER-PEREIRA, 2012).

De acordo com Bresser-Pereira (2005), esta reforma foi compreendida em três dimensões, de acordo com o Quadro 1.

Quadro 1 - Dimensões da reforma da gestão pública

\begin{tabular}{|c|l|}
\hline Dimensões & \multicolumn{1}{c|}{ Descrição } \\
\hline Institucional-Legal & $\begin{array}{l}\text { Voltada à descentralização da estrutura organizacional do aparelho do Estado } \\
\text { através da criação de novos formatos organizacionais, como as agências executi- } \\
\text { vas, regulatórias, e as organizações sociais. }\end{array}$ \\
\hline Gestão & $\begin{array}{l}\text { Definida pela maior autonomia e a introdução de três novas formas de responsa- } \\
\text { bilização dos gestores a administração por resultados, a competição administrada } \\
\text { por excelência, e o controle social - em substituição parcial dos regulamentos rí- } \\
\text { gidos, da supervisão e da auditoria, que caracterizam a administração burocrática. }\end{array}$ \\
\hline Cultural & $\begin{array}{l}\text { Mudança de mentalidade, visando passar da desconfiança generalizada que carac- } \\
\text { teriza a administração burocrática para uma confiança maior, anda que limitada, } \\
\text { própria da administração gerencial. }\end{array}$ \\
\hline
\end{tabular}

Fonte: Adaptado de Bresser-Pereira (2005).

Da gestão da iniciativa privada foram adotados valores perseguidos pela gestão, como, a eficiência, avaliação de desempenho, qualidade, planejamento estratégico e flexibilidade gerencial. Tais valores demonstram grande importância ao serem aplicados no setor privado. Entretanto, existem outros conceitos e valores que se fazem necessários na administração pública, que são: accountability, participação política, transparência, equidade e justiça (ABRUCIO, 1997). Para Bovaird e Löffler (2003), depois de muitos anos de especulação sobre a possibilidade do mercado assumir muito do seu papel, um governo forte e democrático é agora em geral visto como um elemento essencial para a sociedade. Além do mais, a qualidade dos serviços públicos é o principal assunto eleitoral na maioria dos países de todo o mundo (BOVAIRD; LÖFFLER, 2003).

Entretanto, para França Filho (2008) a gestão pública diz respeito àquele modo de gestão praticado no seio das instituições públicas de Estado nas suas mais variadas instâncias. Ainda, segundo o autor, esse modo de gestão distingue-se, consideravelmente, do modelo da gestão privada quanto à natureza dos objetivos perseguidos, mesmo assim, aproxima-se dele em relação ao modo de operacionalizar a gestão, que se assentam numa lógica de poder segundo os parâmetros de uma racionalidade instrumental e técnica. Entretanto, o atendimento à população deve ser o melhor possível, objetivando sempre o ideal, mesmo porque, na própria Constituição Federal do Brasil estabelece-se o princípio da eficiência no atendimento público, conforme relata Rosa (2001, p. 15). 


\begin{abstract}
O último princípio expresso no caput do Art. 37 da CF é o da eficiência, que também abarca dois entendimentos possíveis: tange ao agente público, que não pode atuar amadoristicamente, devendo buscar a consecução do melhor resultado possível, como também diz respeito à forma de organização da Administração Pública, que deve atentar para os padrões modernos de gestão ou administração, vencendo o peso burocrático, atualizando-se e modernizando-se. Com relação à exigência de eficiência, há duas normas expressas que a consagram no próprio texto constitucional: a avaliação periódica de desempenho a que está submetido o servidor; e a possibilidade de formalização de contratos de gestão, as organizações sociais e as agências executivas e outras formas de modernização [...].
\end{abstract}

Para atender de maneira eficiente, a gestão pública deverá estar o mais próximo possível da população. Para os pioneiros sobre economia do setor público e do federalismo fiscal, dentre eles, Tiebout (1956) e Oates (1972) reconhecem que a descentralização fiscal e as transferências intergovernamentais são importantes instrumentos para aumentar a eficiência do tratamento dos recursos públicos dos estados e municípios e obtendo melhores resultados para o bem-estar social da sua população. No item seguinte é tratado sobre a descentralização fiscal e as transferências Intergovernamentais.

\title{
2.2 Descentralização fiscal e transferências intragovernamentais
}

De acordo Zmitrowicz, Biscaro e Marins (2013) a partir de 1988, com a Constituição Federal (CF), os municípios obtiveram autonomia na deliberação e execução dos interesses locais, independentemente de qualquer aprovação nos níveis Estadual ou Federal, sob os aspectos políticos administrativos em relação as suas finanças. Segundo Meirelles (1997) a CF de 1988 garantiu aos municípios o poder de editar a Lei Orgânica Municipal. Que, entre outras regras, define a gestão financeira e tributária do município, além da adoção de políticas para o desenvolvimento em diversos setores do município (ZMITROWICZ; BISCARO; MARINS, 2013).

Os municípios possuem fontes de recursos financeiros que advém de três principais fontes: as próprias, por meio de impostos e taxas de competência municipal; dos recursos financeiros, advindos das transferências intragovernamentais; de impostos de competências estadual e federal, de acordo com a legislação vigente da Constituição Federal; e, de recursos financeiros, advindos de empréstimos e financiamentos (ZMITROWICZ; BISCARO; MARINS, 2013).

Há três tipos, fundamentais, de transferências governamentais, conforme descreve Mendes (2004): as transferências incondicionais sem contrapartida; as condicionais sem contrapartida; e, as condicionais com contrapartida e ilimitada. As transferências intergovernamentais incondicionais são aquelas em que os recursos são transferidos sem o estabelecimento de critérios específicos quanto ao local e forma de aplicação, não vinculando os recursos a gastos prédeterminados (MENDES, 2004). Por outro lado, segue o autor, as transferências condicionais sem contrapartida compreendem o conjunto de recursos, que ao serem transferidos têm-se como exigência o estabelecimento da forma de aplicação do mesmo. Enquanto que, as transferências condicionais com contrapartida, além do estabelecimento da forma de aplicação, devem ter definido um percentual a ser aplicado como contrapartida do recurso recebido (MENDES, 2004).

De acordo com Motta (2007) a gestão pública deve agir no sentido de manter a igualdade perante a Lei e de garantir oportunidades iguais, salvo nos casos em que as chances não são claramente iguais. Em razão da proximidade com a população, o gestor municipal possui melhor condição de gerenciar os recursos financeiros transferidos ao município para que atenda de maneira mais eficiente os anseios da comunidade (MENDES, 2004). 


\subsection{Estudos anteriores}

Com a finalidade de estabelecer um conhecimento prévio e facilitar o entendimento e a compreensão a respeito da temática, se identificou estudos anteriores que abordaram assuntos correlatos à temática desenvolvida neste artigo, no Quadro 2 descreve-se os estudos em que se identifica os autores, ano de publicação do estudo, o título, os objetivos e os principais resultados revelados pelos autores dos estudos.

Quadro 2 - Estudos anteriores sobre gestão públicas e desenvolvimento Municipal.

\begin{tabular}{|c|c|c|c|}
\hline Autores & Título & Objetivo & Resultados dos estudos \\
\hline Pacheco (2003) & $\begin{array}{l}\text { Aplicação e os impactos } \\
\text { dos royalties do petró- } \\
\text { leo no desenvolvimento } \\
\text { econômico dos municí- } \\
\text { pios confrontantes da } \\
\text { Bacia de Campos }\end{array}$ & $\begin{array}{l}\text { Realizar um estudo sobre } \\
\text { a importância dos recursos } \\
\text { nas receitas dos municípios } \\
\text { confrontantes da Bacia de } \\
\text { Campos, no Estado do Rio } \\
\text { de Janeiro. O ponto principal } \\
\text { de análise é verificar de que } \\
\text { maneira os benefícios estão } \\
\text { sendo utilizados pelas Admi- } \\
\text { nistrações Municipais, quais } \\
\text { são os resultados dos inves- } \\
\text { timentos que já podem ser } \\
\text { percebidos e analisar a sus- } \\
\text { tentabilidade dos mesmos. }\end{array}$ & $\begin{array}{l}\text { Obteve-se a confirmação de que os royal- } \\
\text { ties e participações especiais estão pos- } \\
\text { sibilitando maiores investimentos em } \\
\text { infraestrutura nos municípios contem- } \\
\text { plados e, da mesma forma, estão sendo } \\
\text { utilizados para fornecer, aos governos lo- } \\
\text { cais, os recursos necessários para suprir a } \\
\text { demanda excessiva por serviços públicos. } \\
\text { Ao mesmo tempo, não se verificou ações } \\
\text { concretas para a promoção de um proje- } \\
\text { to de sustentabilidade e de diversificação } \\
\text { da base produtiva local, de modo a pre- } \\
\text { venir o declínio econômico, decorrente } \\
\text { da exaustão das reservas de hidrocarbo- } \\
\text { netos. }\end{array}$ \\
\hline Coutinho (2006) & $\begin{array}{l}\text { Os impactos dos royal- } \\
\text { ties petrolíferos sobre } \\
\text { o desenvolvimento } \\
\text { econômico local: Um } \\
\text { estudo comparativo } \\
\text { entre os municípios de } \\
\text { Campos dos Goytacazes } \\
\text { e Niterói }\end{array}$ & $\begin{array}{l}\text { Objetiva elucidar os fatores } \\
\text { que atuam sobre a escolha } \\
\text { dos padrões de alocação dos } \\
\text { recursos públicos nos municí- } \\
\text { pios de Campos dos Goytaca- } \\
\text { zes e Niterói. }\end{array}$ & $\begin{array}{l}\text { Demonstrar, através de comparação, que } \\
\text { as formas de arrecadação, combinadas } \\
\text { a elementos políticos como a interação } \\
\text { entre os grupos de pressão e as institui- } \\
\text { ções locais, geram padrões de alocações } \\
\text { que contribuem ou prejudicam o fortale- } \\
\text { cimento e o dinamismo das economias } \\
\text { locais. }\end{array}$ \\
\hline $\begin{array}{l}\text { Matos Filho e } \\
\text { Silva (2008) }\end{array}$ & $\begin{array}{l}\text { O Gasto Público nos } \\
\text { Municípios Produtores } \\
\text { de Petróleo no Estado } \\
\text { do Rio Grande do Nor- } \\
\text { te: uma Avaliação dos } \\
\text { Efeitos dos Royalties so- } \\
\text { bre o Desempenho das } \\
\text { Finanças e das Políticas } \\
\text { Públicas. }\end{array}$ & $\begin{array}{l}\text { Utiliza a teoria normativa do } \\
\text { federalismo fiscal para carac- } \\
\text { terizar os principais tipos de } \\
\text { transferências intergoverna- } \\
\text { mentais, e os conceitos re- } \\
\text { lacionados com a avaliação } \\
\text { de políticas públicas sob o } \\
\text { ponto de vista do gasto e do } \\
\text { financiamento, com base nos } \\
\text { quais constrói índices para } \\
\text { mensurar os referidos efeitos. }\end{array}$ & $\begin{array}{l}\text { Verifica que os royalties foram responsá- } \\
\text { veis pelo crescimento das receitas e dos } \\
\text { gastos sociais nos municípios pesquisa- } \\
\text { dos, porém isto não significou aumento } \\
\text { automático no grau de autonomia das } \\
\text { finanças municipais nem melhoria gene- } \\
\text { ralizada nas condições sociais da popula- } \\
\text { ção. } \\
\text { Ao contrário, trata-se de uma trajetória } \\
\text { marcada por caminhos e descaminhos. } \\
\text { Caminhos, que levam ao aumento do } \\
\text { gasto em políticas sociais como educa- } \\
\text { ção, saúde, habitação e assistência social. } \\
\text { Descaminhos, que levam à permanência } \\
\text { de elevados graus de pobreza, de analfa- } \\
\text { betismo e de evasão escolar e ao recru- } \\
\text { descimento de doenças de notificação } \\
\text { compulsória, como tuberculose, dengue } \\
\text { e hepatite. }\end{array}$ \\
\hline
\end{tabular}




\begin{tabular}{|c|c|c|c|}
\hline Autores & Título & Objetivo & Resultados dos estudos \\
\hline $\begin{array}{l}\text { Moreira e Aze- } \\
\text { vedo (2009) }\end{array}$ & $\begin{array}{l}\text { Gestão Pública: entre } \\
\text { a visão clássica da Ad- } \\
\text { ministração Pública e o } \\
\text { novo paradigma da Go- } \\
\text { vernação Pública }\end{array}$ & $\begin{array}{l}\text { Acompanhar a evolução de } \\
\text { um movimento reformista } \\
\text { que vai da Administração Pú- } \\
\text { blica a Governação, passando } \\
\text { pela Nova Gestão Pública. }\end{array}$ & $\begin{array}{l}\text { Identificou que toda a problemática refe } \\
\text { rente aos "estudos públicos" e à neces } \\
\text { sidade de reforma do Estado e da Admi- } \\
\text { nistração Pública tem natureza interdis } \\
\text { ciplinar e uma forte vertente de ciências } \\
\text { aplicadas. } \\
\text { Várias áreas que tradicionalmente mere } \\
\text { ciam pouca atenção no âmbito das Ciên } \\
\text { cias da Administração são hoje cruciais. } \\
\text { A rápida alteração das relações e frontei } \\
\text { ras entre Estado, mercado e sociedade } \\
\text { civil exigem mais do que nunca a articu } \\
\text { lação entre ética, capital social e a presta- } \\
\text { ção de serviços públicos. }\end{array}$ \\
\hline Zapelini (2011) & $\begin{array}{l}\text { As "big questions" da } \\
\text { administração pública: } \\
\text { uma proposta para o } \\
\text { caso brasileiro }\end{array}$ & $\begin{array}{l}\text { Recuperar o debate ocorrido } \\
\text { nos Estados Unidos em torno } \\
\text { das big questions ou questões } \\
\text { centrais que norteiam o estu- } \\
\text { do da Administração Pública, } \\
\text { para, a partir disso, trabalhar } \\
\text { com uma proposta de ques- } \\
\text { tões para o caso específico do } \\
\text { Brasil. }\end{array}$ & $\begin{array}{l}\text { Observou-se a inexistência de um con } \\
\text { senso entre os autores sobre quais de } \\
\text { vam ser essas questões, ainda que se } \\
\text { perceba uma concentração dos estudos e } \\
\text { debates em determinados temas. } \\
\text { Desenvolve-se uma proposta de ques } \\
\text { tões centrais, relacionadas ao problema } \\
\text { da atuação da Administração Pública na } \\
\text { sociedade como produtora de bens e ser } \\
\text { viços e como indutora do desenvolvimen } \\
\text { to econômico, à relação entre burocracia } \\
\text { e democracia, e ao foco do estudo que } \\
\text { deve ser utilizado. }\end{array}$ \\
\hline $\begin{array}{l}\text { Cardoso JR. } \\
\quad(2011)\end{array}$ & $\begin{array}{l}\text { Planejamento governa- } \\
\text { mental e gestão públi- } \\
\text { ca no Brasil: elementos } \\
\text { para ressignificar o de- } \\
\text { bate e capacitar o es- } \\
\text { tado. }\end{array}$ & $\begin{array}{l}\text { Revisitar a discussão sobre } \\
\text { planejamento e gestão no } \\
\text { Brasil e remete sobre as pos- } \\
\text { sibilidades atuais de recon- } \\
\text { ciliação entre essas funções } \\
\text { contemporâneas do Estado } \\
\text { na promoção do desenvolvi- } \\
\text { mento nacional. }\end{array}$ & $\begin{array}{l}\text { Apresenta a necessidade de se avançar } \\
\text { na compreensão do tema, sugerem que } \\
\text { as dimensões do planejamento e da ges } \\
\text { tão das políticas públicas para o desen } \\
\text { volvimento estão de volta ao centro do } \\
\text { debate nacional e dos circuitos de deci } \\
\text { sões governamentais. }\end{array}$ \\
\hline Farah (2011) & $\begin{array}{l}\text { Administração pública e } \\
\text { políticas públicas }\end{array}$ & $\begin{array}{l}\text { Realizar uma análise da incor- } \\
\text { poração das políticas públicas } \\
\text { (PP) pela administração pú- } \\
\text { blica (AP) nos EUA e no Brasil. }\end{array}$ & $\begin{array}{l}\text { Inicialmente, nos EUA, as PP não foram } \\
\text { objeto da AP, dado o paradigma que pre } \\
\text { sidiu a criação da disciplina, o da adminis } \\
\text { tração científica, nos anos } 1960 \text { e } 1970 \\
\text { o movimento de análise de políticas pú } \\
\text { blicas levou à constituição de escolas } \\
\text { cursos de PP e à reformulação de cursos } \\
\text { e programas de AP. } \\
\text { Estes passaram a incluir disciplinas de po } \\
\text { líticas públicas, enquanto os novos cursos } \\
\text { de PP incluíram disciplinas de gestão pú } \\
\text { blica. As políticas públicas foram incorpo } \\
\text { radas pela AP no Brasil ao mesmo tempo } \\
\text { em que nos EUA, sob a influência daquele } \\
\text { país. } \\
\text { Tal incorporação refletiu, porém, espe } \\
\text { cificidades da disciplina em nosso país } \\
\text { presença do desenvolvimentismo; valori } \\
\text { zação do planejamento; contexto ditato } \\
\text { rial e tensão derivada da inserção institu- } \\
\text { cional da AP }\end{array}$ \\
\hline
\end{tabular}




\begin{tabular}{|c|c|c|c|}
\hline Autores & Título & Objetivo & Resultados dos estudos \\
\hline Torres (2013) & $\begin{array}{c}\text { Desigualdades econô- } \\
\text { micas interregionais, } \\
\text { capacidade tributária e } \\
\text { esforço fiscal dos esta- } \\
\text { dos e renda per capita } \\
1995 \text { a } 2012\end{array}$ & $\begin{array}{l}\text { Analisar se houve melhora } \\
\text { na acentuada desigualdade } \\
\text { regional em face da melhoria } \\
\text { no ambiente macroeconô- } \\
\text { mico no Brasil após meados } \\
\text { dos anos 90, no que tange } \\
\text { aos efeitos das desigualda- } \\
\text { des econômicas (inter/intra) } \\
\text { regionais correlacionando } \\
\text { a capacidade fiscal (Receita } \\
\text { Corrente, ICMS e FPE) e ren- } \\
\text { da per capita na esfera do } \\
\text { federalismo fiscal. }\end{array}$ & $\begin{array}{l}\text { O estudo analisou os resultados da me- } \\
\text { dição da capacidade da arrecadação tri- } \\
\text { butária dos estados brasileiros, com des- } \\
\text { taque para os estados da região Norte e } \\
\text { Nordeste para o período de } 1995 \text { a } 2012 \text {. } \\
\text { A análise demonstra o modelo de esgo- } \\
\text { tamento do incremento da arrecadação } \\
\text { do ICMS em percentual do PIB e em pre- } \\
\text { ços constantes. Avaliou-se que se mante- } \\
\text { ve a alta heterogeneidade da capacidade } \\
\text { fiscal entre a receita corrente per capita } \\
\text { do Brasil em relação aos estados da } \\
\text { região Nordeste e Norte, bem como a } \\
\text { desigualdade da renda per capita. }\end{array}$ \\
\hline Moratta (2015) & $\begin{array}{l}\text { A participação das } \\
\text { transferências intergo- } \\
\text { vernamentais no cresci- } \\
\text { mento econômico dos } \\
\text { municípios: um estudo } \\
\text { no Estado de Santa } \\
\text { Catarina. }\end{array}$ & $\begin{array}{l}\text { Identificar a (in) dependência } \\
\text { orçamentária em relação às } \\
\text { transferências intergoverna- } \\
\text { mentais dos Municípios com } \\
\text { até } 10.000 \text { habitantes no Es- } \\
\text { tado de Santa Catarina e seu } \\
\text { reflexo para o crescimento } \\
\text { econômico. }\end{array}$ & $\begin{array}{l}\text { Demonstrou a dependência municipal } \\
\text { com as transferências e que, na média } \\
\text { da amostra, no período de } 2008 \text { a 2012, } \\
\text { teve representatividade acima de } 89 \% \text {, } \\
\text { exceto para o ano de } 2010 \text { quando esse } \\
\text { valor corresponde a } 76,38 \% \text {, sendo a } \\
\text { União a principal origem dessas transfe- } \\
\text { rências. Em relação à evolução do PIB, } \\
\text { no período da pesquisa, foi de } 11 \% \text {. O } \\
\text { resultado final é que a dependência dos } \\
\text { Municípios em relação às transferências } \\
\text { intergovernamentais não influencia o } \\
\text { crescimento econômico. }\end{array}$ \\
\hline
\end{tabular}

Fonte: Elaborado pelos autores.

\section{PROCEDIMENTOS METODOLÓGICOS}

O presente estudo teve como objetivo analisar a relação entre os repasses de recursos estaduais e federais no desenvolvimento dos municípios de Santa Catarina. Para isso, foram levantados dados sobre os repasses de recursos estaduais (ICMS) e Federais (FUNDEB e FPM), recebidos pelos municípios no período de 2008 a 2011. Desta forma, a pesquisa caracteriza-se como descritiva quanto os objetivos, esse tipo de pesquisa trata de esclarecer determinado aspecto e/ou características de determinada ciência (RAUPP; BEUREN, 2008). Quando empregável a pesquisa descritiva há a preocupação do pesquisador com a observação dos fatos, seus registros, a análise, classificação e interpretação (ANDRADE, 2002). Já quanto à abordagem, a pesquisa foi caracterizada como quantitativa.

Os dados foram obtidos por meio de dados secundários, incialmente, buscou-se os valores do IFDM de cada município pesquisado, por meio da divulgação deste indicador no site da FIRJAN. Os dados relativos aos repasses recebidos pelo município foram obtidos por meio de coleta, junto ao Portal de Transferências de Santa Catarina mantido pela Federação Catarinense de Municípios (FECAM). Este procedimento é considerado como pesquisa documental, que se baseia em materiais que ainda não foram analisados ou que podem ser reelaborados de acordo com os objetivos da pesquisa (RAUPP; BEUREN, 2008).

As informações obtidas foram tratadas no software Microsoft Excel e analisadas no software Statistical Package for the Social Sciences (SPSS) 20.0. A população de estudo são os 293 municípios de Santa Catarina, a escolha destes municípios foi intencional e não probabilística. Duas hipóteses de pesquisa foram estabelecidas. 
$\mathrm{H}_{1}$ : Há relação entre os recursos recebidos pelos municípios e o desenvolvimento municipal.

$\mathrm{H}_{2}$ : Os municípios com maiores recursos têm melhores índices de desenvolvimento, continuamente. o IFDM

Com o propósito de validar ou negar as hipóteses, foram realizados os cálculos de correlação de Pearson entre os recursos recebidos entre os anos de 2008 a 2011 com o IFDM divulgado em 2012, em busca de verificar como o IFDM e os recursos se correlacionam nos municípios catarinenses. Entretanto a correlação de Pearson só pode ser aceita se houver normalidade nos dados da amostra. Desta maneira, fez-se o teste não paramétrico Kolmogorov-Smirnov para verificar a normalidade dos dados.

Após, o cálculo da correlação efetuou-se o cálculo da regressão linear múltipla. Desta forma, buscou-se medir a seguinte equação linear:

IFDM $=$ ICMS. $\alpha+$ FUNDEB. $\beta+$ FPM. $\gamma+\varepsilon$

Em que:

IFDM = valor do IFDM do munícipio

ICMS = Valor do ICMS arrecadado por munícipio

FUNDEB $=$ Valor do FUNDEB arrecadado por munícipio

$\mathrm{FPM}=$ Valor do FPM arrecadado por munícipio

$A, \beta$ e $\nu=$ constantes;

$\varepsilon=$ erro da regressão.

A equação, gerada pela regressão linear múltipla, possibilitou realizar uma projeção dos indicadores IFDM, dos cinquenta municípios com maior IFDM do estado de Santa Catarina para os anos de 2013 e 2014, com base nos valores recebidos pelos municípios em 2011 e 2012. A utilização de dados de dois anos anteriores se faz necessário, uma vez que, o IFDM tem sempre dois anos de atraso em sua divulgação em relação aos recursos investidos. Ou seja, os indicadores divulgados de 2013 e 2014 devem ser apurados utilizando os dados de recursos de 2011 e 2012, respectivamente.

\section{ANÁLISE DOS RESULTADOS}

Para analisar o impacto no desenvolvimento dos municípios de Santa Catarina, ocasionados por meio do repasse de recursos estaduais e federais no período estudado, conforme apresentado na metodologia, foram analisados, ao todo, quatro variáveis. A estatística descritiva das variáveis é apresentada na Tabela 2.

Tabela 1 - Estatística descritiva das variáveis

\begin{tabular}{c|c|c|c|c}
\hline Variáveis & Mínimo & Máximo & Média & Desvio padrão \\
\hline IFDM & 0,574 & 0,885 & 0,718 & 0,061 \\
\hline ICMS & 1.307 .462 & 204.253 .848 & 7.410 .912 & 17.765 .670 \\
\hline FUNDEB & 234.096 & 124.961 .448 & 4.796 .966 & 11.255 .830 \\
\hline FPM & 3.272 .314 & 56.529 .652 & 5.630 .038 & 5.588 .702 \\
\hline
\end{tabular}

Fonte: Dados da pesquisa. 
Pode ser verificado a partir da Tabela 1 que o índice IFDM, que concentra os resultados alcançados pela educação, trabalho e renda, dos municípios de todo o país, apresentou uma baixa dispersão, como pode ser observado pelos valores obtidos pela média e desvios padrão. Já as variáveis ICMS, FUNDEB e FPM apresentaram uma maior heterogeneidade. É possível verificar ainda que o ICMS possui a maior intensidade nos valores observados em comparação com as outras variáveis, como pode ser verificado pelos valores de mínimo em $\mathrm{R} \$ 1.307 .462$ e o máximo em $R \$ 204.253 .848$, ocasionado em parte pela presença de municípios com arrecadação elevada, originada pela maior circulação de produtos e serviços.

Antes de efetuar a análise de regressão linear múltipla, o estudo buscou analisar inicialmente a intensidade e o sentido das relações entre as variáveis, calculou-se o coeficiente de Correlação de Pearson para as variáveis. Ressalta-se que foi aplicado o teste não paramétrico de Kolmogorov-Smirnov para verificar a normalidade dos dados, o teste evidenciou uma distribuição normal das variáveis em nível de $5 \%$ ( $p$-value< 0.05 ). Observa-se que a correlação não sugere necessariamente uma relação de causa e efeito, mas na associação entre as variáveis. A Tabela 2 apresenta a correlação de Pearson entre as variáveis.

Tabela 2 - Correlação de Pearson entre as variáveis

\begin{tabular}{c|c|c|c|c}
\hline Variável & IFDM & ICMS & FUNDEB & FPM \\
\hline IFDM & 1,0000 & & & \\
\hline ICMS & $0,459^{*}$ & 1,0000 & & \\
\hline FUNDEB & $0,475^{*}$ & $0,951^{*}$ & 1,0000 & \\
\hline FPM & $0,506^{*}$ & $0,774^{*}$ & $0,862^{*}$ & 1,0000 \\
\hline
\end{tabular}

*A correlação é significativa no nível $1 \%$.

Fonte: Dados da pesquisa.

De acordo com a Tabela 2, a matriz de correlação apresenta que todas variáveis independentes possuem correlação positiva estatisticamente e significativa com a variável dependente, IFDM, a saber: ICMS $(r=0,459 ; p$-value $<0,01)$, FUNDEB $(r=0,475 ; p$-value $<0,01)$ e FPM ( $r$ $=0,506 ; p$-value $<0,01)$. A baixa correlação entre as variáveis independentes com a dependente ocorre do fato de que outros fatores afetam o desenvolvimento dos municípios, ou seja, além do volume de recursos, fatores como: qualidade de gestão; gastos com a "máquina" pública; investimentos privados no município; entre outros, podem estar correlacionados com os valores do Índice Firjan de Desenvolvimento Municipal, visto que o IFDM é calculado com base no investimento feito em saúde, educação e níveis de emprego e renda dos municípios.

Após o cálculo da correlação de Pearson entre as variáveis independentes com a dependente, partiu-se para a análise da regressão linear múltipla. A regressão apresentou a ocorrência de multicolinearidade entre as variáveis FUNDEB e ICMS $(r=0,951 ; p$-value $<0,01)$ e entre a FUNDEB e FPM $(r=0,862 ; p$-value $<0,01)$. O que pode refletir nos resultados apurados, afetando o modelo da regressão e acarretar na diminuição do poder preditivo das variáveis, sendo assim, foi retirado do modelo de regressão a variável FUNDEB. Dessa forma, por meio da regressão linear múltipla, buscou-se verificar com variáveis ICMS e FPM, se estas explicam o impacto dos repasses de recursos no desenvolvimento dos municípios de Santa Catarina. A Tabela 3 apresenta o resumo do modelo. 
Tabela 3 - Resumo do modelo

\begin{tabular}{cccccc}
\hline Modelo & $\mathbf{R}$ & $\mathbf{R}$ quadrado & R quadrado ajustado & Erro padrão da estimativa & Durbin-Watson \\
\hline 1 & 0,517 & 0,267 & 0,262 & 0,0525 & 1,984
\end{tabular}

Fonte: Dados da pesquisa.

Na Tabela 3 a estatística de Durbin-Watson informa se a hipótese de independência dos erros é satisfeita, conforme Maroco (2007) o valor deve estar próximo de 2. Conforme a Tabela 3 é possível observar que o modelo não apresenta problemas de autocorrelação dos resíduos, pois seu valor 1,984 está próximo de 2, possibilitando aceitar a hipótese de independência do erro. A Tabela 3 descreve ainda o modelo globalmente, ela informa se o modelo é eficaz em prever o índice FIRJAN. O coeficiente de determinação $\left(R^{2}\right)$ serve como uma medida de quanto a variabilidade da saída pode ser debitada aos previsores. O modelo, apresentado na tabela 4 , demonstra um $R^{2}$ de 0,267 , o que significa que as variáveis independentes são responsáveis por $26,7 \%$ da variação do índice FIRJAN.

Pelos valores do coeficiente de determinação é possível também inferir, que a variável dependente IFDM, não é totalmente explicada pelas variáveis independentes (ICMS e FPM) o que leva a crer que outros fatores influenciam no resultado do indicador de desenvolvimento do município, entre eles, outros recursos ou até mesmo a qualidade de gestão.

De acordo com os resultados encontrados pelos estudos de Moratta (2015) o desenvolvimento econômico dos municípios catarinenses não é impactado pelas transferências intragovernamental. $\mathrm{O}$ que coaduna com os resultados encontrados nesse estudo, em que há baixa explicação do IFDM pelas transferências de recursos (26,7\%).

A Tabela 4 apresenta a análise de variância, que testa se o modelo possui um poder explicativo melhor do que a média, para explicar a variável independente.

Tabela 4 - Análise de variância

\begin{tabular}{c|c|c|c|c|c}
\hline Modelo & Soma dos Quadrados & df & Quadrado Médio & F & Sig. \\
\hline Regressão & 0,289 & 3 & 0,144 & 52,473 & 0,000 \\
\hline Resíduos & 0,793 & 288 & 0,003 & & \\
\hline Total & $\mathbf{1 , 0 8 2}$ & $\mathbf{2 9 0}$ & & &
\end{tabular}

Fonte: Dados da pesquisa.

Conforme os resultados apresentados pela análise de variância por meio do teste $\mathrm{F}$ (Tabela 4) pode-se afirmar que há um nível de significância de $1 \%$ ( $p$-value $<0,01$ ), descrevendo que existe uma forte evidência que as variáveis independentes influenciam, significativamente, com o resultado do indicador de desenvolvimento dos municípios. Até o momento, foi verificado se o modelo melhorou ou não a previsão do indicador de desenvolvimento do município.

Por fim, na tabela 5, apresentam-se os coeficientes de regressão múltipla, com o objetivo de descrever a equação da regressão.

Tabela 5 - Coeficiente de regressão múltipla

\begin{tabular}{|c|c|c|c|c|c|}
\hline \multirow{2}{*}{ Modelo } & \multicolumn{2}{|c|}{ Coeficientes não padronizados } & \multirow{2}{*}{$\begin{array}{c}\text { Coeficientes padronizados } \\
\text { Beta }\end{array}$} & \multirow{2}{*}{$\mathbf{t}$} & \multirow{2}{*}{ Sig. } \\
\hline & B & Modelo padrão & & & \\
\hline (Constante) & 0,691 & 0,005 & & 146,628 & 0,000 \\
\hline ICMS & $5,771 \mathrm{E}-010$ & 0,000 & 0,168 & 2,108 & 0,036 \\
\hline FPM & $4,108 \mathrm{E}-009$ & 0,000 & 0,376 & 4,722 & 0,000 \\
\hline
\end{tabular}

Fonte: Dados da pesquisa. 
Segundo a Tabela 5, as variáveis independentes foram consideradas estatisticamente significantes ao de nível de $1 \%$ ( $p$-value $<0,01)$ para a constante e a variável FPM, o ICMS é considerado pelo estudo, significativo estatisticamente ao nível de $5 \%$ ( $p$-value $<0,05)$. Desta forma, verificou-se que o fundo de participação dos municípios (FPM) e o imposto sobre a circulação de mercadorias e serviços (ICMS), impactam positivamente no índice FIRJAN de desenvolvimento municipal (IFDM). O que possibilita, de acordo com a Tabela 5, estabelecer a seguinte equação de regressão.

Com o estabelecimento da equação de regressão foi possível elaborar uma previsão para os anos de 2013 e 2014 do IFDM em que se levaram em consideração os valores de recursos repassados aos municípios em 2011 e 2012 para prever 2013 e 2014, respectivamente. A Tabela 6 demonstra o valor da previsão para os 50 municípios com melhores IFDM em 2012 e o ranking de recursos.

Tabela 6 - Previsão do IFDM de 2013 e 2014

\begin{tabular}{|c|c|c|c|c|c|c|c|}
\hline $\begin{array}{l}\text { Ranking } \\
\text { (2012) }\end{array}$ & Cidade & $\begin{array}{l}\text { Ranking de recursos } \\
(2010)\end{array}$ & IFDM (2012) & $\begin{array}{l}\text { Ranking } \\
\text { (2013) }\end{array}$ & IFDM (2013) & $\begin{array}{l}\text { Ranking } \\
\text { (2014) }\end{array}$ & $\begin{array}{l}\text { IFDM } \\
(2014) \\
\end{array}$ \\
\hline 1 & Blumenau & 3 & 0,8849 & 4 & 0,9095 & 4 & 0,9040 \\
\hline 3 & Florianópolis & 4 & 0,8737 & 1 & 1,0329 & 1 & 0,9997 \\
\hline 4 & Joinville & 1 & 0,8727 & 2 & 0,9712 & 2 & 0,9620 \\
\hline 6 & Pomerode & 30 & 0,8559 & 40 & 0,7396 & 43 & 0,7381 \\
\hline 7 & Jaraguá do Sul & 5 & 0,8541 & 5 & 0,8914 & 5 & 0,8775 \\
\hline 8 & Concórdia & 14 & 0,8462 & 15 & 0,7716 & 18 & 0,7675 \\
\hline 9 & Tubarão & 13 & 0,8451 & 13 & 0,7860 & 14 & 0,7792 \\
\hline 10 & Balneário Camboriú & 19 & 0,8433 & 12 & 0,7897 & 12 & 0,7946 \\
\hline 14 & Tigrinhos & 279 & 0,8350 & 271 & 0,7081 & 165 & 0,7116 \\
\hline 15 & Rio do Sul & 22 & 0,8317 & 17 & 0,7679 & 20 & 0,7627 \\
\hline 16 & Timbó & 26 & 0,8274 & 36 & 0,7449 & 34 & 0,7469 \\
\hline 17 & Tijucas & 41 & 0,8266 & 38 & 0,7407 & 42 & 0,7391 \\
\hline 18 & Criciúma & 9 & 0,8224 & 9 & 0,8609 & 9 & 0,8485 \\
\hline 19 & Gaspar & 24 & 0,8196 & 21 & 0,7617 & 22 & 0,7605 \\
\hline 20 & Indaial & 23 & 0,8148 & 20 & 0,7624 & 24 & 0,7587 \\
\hline 21 & Maravilha & 58 & 0,8135 & 58 & 0,7280 & 72 & 0,7268 \\
\hline 28 & São José & 6 & 0,7966 & 6 & 0,8680 & 6 & 0,8548 \\
\hline 29 & Antônio Carlos & 89 & 0,7965 & 125 & 0,7109 & 164 & 0,7116 \\
\hline 30 & Itá & 36 & 0,7964 & 92 & 0,7173 & 120 & 0,7161 \\
\hline 31 & São Bento do Sul & 12 & 0,7959 & 14 & 0,7781 & 16 & 0,7722 \\
\hline 32 & Corupá & 91 & 0,7953 & 80 & 0,7212 & 86 & 0,7225 \\
\hline 33 & Urussanga & 50 & 0,7940 & 54 & 0,7288 & 65 & 0,7282 \\
\hline 34 & Schroeder & 84 & 0,7909 & 84 & 0,7211 & 95 & 0,7207 \\
\hline 35 & Alto Bela Vista & 237 & 0,7882 & 237 & 0,7083 & 261 & 0,7090 \\
\hline 36 & Orleans & 55 & 0,7875 & 56 & 0,7283 & 70 & 0,7274 \\
\hline 37 & Novo Horizonte & 230 & 0,7868 & 227 & 0,7084 & 194 & 0,7102 \\
\hline 38 & Massaranduba & 76 & 0,7858 & 79 & 0,7217 & 92 & 0,7214 \\
\hline 39 & Camboriú & 43 & 0,7837 & 26 & 0,7595 & 31 & 0,7548 \\
\hline
\end{tabular}




\begin{tabular}{c|c|c|c|c|c|c|c}
\hline 40 & Navegantes & 33 & 0,7834 & 28 & 0,7578 & 23 & 0,7605 \\
\hline 41 & Braço do Norte & 51 & 0,7830 & 44 & 0,7332 & 54 & 0,7315 \\
\hline 42 & Biguaçu & 17 & 0,7823 & 18 & 0,7664 & 21 & 0,7627 \\
\hline 43 & Videira & 15 & 0,7821 & 22 & 0,7615 & 26 & 0,7570 \\
\hline 44 & Araquari & 72 & 0,7811 & 46 & 0,7327 & 48 & 0,7350 \\
\hline 45 & Caibi & 153 & 0,7807 & 156 & 0,7093 & 103 & 0,7193 \\
\hline 46 & Nova Erechim & 147 & 0,7754 & 154 & 0,7093 & 109 & 0,7182 \\
\hline 47 & lomerê & 143 & 0,7747 & 136 & 0,7100 & 108 & 0,7182 \\
\hline 48 & Palmitos & 67 & 0,7742 & 76 & 0,7224 & 93 & 0,7213 \\
\hline 49 & Luzerna & 166 & 0,7736 & 167 & 0,7089 & 182 & 0,7106 \\
\hline 50 & Treze Tílias & 106 & 0,7722 & 4 & 0,7104 & 172 & 0,7112 \\
\hline \hline
\end{tabular}

Fonte: Dados da pesquisa.

Os resultados, apresentados na Tabela 6, revelam que o município de Blumenau ficou em terceira posição com as entradas de recursos em 2010, permanecendo em primeiro colocado no IFDM de 2012. De acordo com a previsão, a cidade de Blumenau deverá permanecer em posições similares nos IFDM de 2013 e 2014. Bem como, a capital do Estado de Santa Catarina, Florianópolis como o quarto município que mais arrecadou recursos, ficou com a terceira posição do IFDM em 2012, alterando para primeira colocada em 2013 e 2014. Por outro lado, Joinville que possui a maior arrecadação do estado, ficou em quarta colocada no IFDM (2012) e na previsão elaborada, foi evidenciada uma tendência de o município ficar com o segundo colocado nos anos de 2013 e 2014.

Entre os dez maiores municípios em arrecadação de recursos, há de se destacar, positivamente, o desempenho do município de Brusque que mesmo por posicionar-se na décima colocação em arrecadação, permaneceu como segundo melhor município de IFDM (2012). Contudo, Brusque deverá se estabelecer na décima posição no IFDM na projeção dos próximos dois anos. Além disso, ocorreu de que entre os dez maiores municípios de arrecadação houvesse um destaque negativo, que é a cidade São José, mesmo possuindo a sexta maior arrecadação do Estado, o seu IFDM de 2012 é o vigésimo oitavo. Porém, foi evidenciada uma previsão de melhora para os períodos de 2013 (6ª ) e 2014 (6a), respectivamente.

Outro município que deve se destacado é Pomerode, que apesar de ter a trigésima arrecadação, possui o quarto melhor desempenho municipal do Estado, entretanto existe um aumento de sua posição, o qual passa ocupar a 40a (2013) e 43a (2014) posição respectivamente. Também se destaca o município de Tigrinhos com a ducentésima nona em arrecadação e uns dos melhores índices de desenvolvimento municipal, o qual ocupa a decima quarta posição em 2012.

Os dados analisados evidenciaram a existência de vários municípios que possuem entrada maior de recursos, entretanto baixos índices de desenvolvimentos. Por outro lado, municípios que não alcançaram valor tão expressivo de arrecadação, apresentam um IFDM melhor. Portanto, novamente os resultados demonstram que os recursos são importantes para o desenvolvimento dos municípios, porém, não são fatores exclusivos de desenvolvimento.

Considerando as hipóteses levantadas, foram elaborados os cálculos de regressão e correlação para aceitá-las ou refutá-las. Tanto os cálculos de regressão linear, quanto o cálculo de correlação de Pearson, demonstraram haver relação entre os recursos recebidos e o índice de desenvolvimento dos municípios. Porém, essa relação não é alta, o que demonstra que outros fatores, além dos recursos arrecadados pelos municípios, impactam o desenvolvimento. Um dos fatores que podem influenciar é a qualidade da gestão dos recursos pelos gestores públicos. Entretanto, essa proposição não foi objeto de análise no estudo. 
Dessa forma é possível aceitar a $\mathrm{H}_{1}$ de que "há relação entre os recursos recebidos pelos $\mathrm{Mu}$ nicípios e o desenvolvimento Municipal". Havia a expectativa que os maiores municípios em captação de recursos teriam os melhores índices de desenvolvimento, contudo, alguns municípios nessa situação não apresentaram os melhores índices. $O$ que pode ser visto que dos 50 municípios com maior arrecadação, somente, 28 se mantém entre os 50 municípios com maiores IFDM em 2012.

Contudo, nos anos seguintes em que foi projetado o IFDM, ocorreram mudanças na posição de algumas cidades que obtiveram pouca arrecadação nesse cenário, o que implica em afirmar que no espaço curto de tempo das projeções, haverá mudanças significativas no indicador de desenvolvimento dos municípios. Dessa forma não é possível aceitar a $\mathrm{H}_{2}$ da pesquisa, que os municípios com maiores recursos têm melhores índices de desenvolvimento, continuamente.

\section{CONSIDERAÇÕES FINAIS}

Este estudo objetivou analisar a relação entre os repasses de recursos estaduais e federais (ICMS, FUNDEB e FPM) no desenvolvimento dos municípios de Santa Catarina. Para tanto, utilizou-se da estatística descritiva, com o intuito de caracterizar os dados da pesquisa. Em seguida foi realizada a correlação de Pearson buscando encontrar relação entre as variáveis. Seguido, da regressão linear múltipla para comprovar. Por fim, foi estabelecido um posicionamento das cidades quanto ao índice IFDM em 2012 e uma projeção para os anos de 2013 e 2014 e o posicionamento dos municípios quanto ao valor total de arrecadação.

Os resultados da correlação demonstraram que há correlação significativa entre as variáveis, mas apresentou uma multicolinearidade entre as variáveis FUNDEB e ICMS e entre a FUNDEB e FPM. Visto que, estes resultados poderiam ter afetado o modelo da regressão e acarretar na diminuição do poder preditivo das variáveis, foi retirado do modelo de regressão a variável FUNDEB. Os resultados encontrados levaram a aceitação da hipótese $\mathrm{H}_{1}$, que pressupunha haver uma relação entre o desenvolvimento dos municípios e a captação de recursos. Contudo outros fatores podem contribuir ao desenvolvimento, além dos recursos, a boa gestão dos recursos, a redução dos gastos para manutenção da "máquina" pública e investimentos privados no município, podem ser fatores que ampliem os investimentos em melhoria da Saúde, educação e geração de emprego e renda, quesitos esses que compõe o IFDM. A regressão linear múltipla, demostrou que o modelo preditor é válido e significativo estatisticamente.

O estudo também observou que o fato de ter um valor maior de recursos não implica, necessariamente, em ter um índice de desenvolvimento municipal (IFDM) maior. Vários municípios com grandes entradas de recursos apresentaram um valor de IFDM (2012) menor que sua posição no ranking de arrecadação, contudo nos cenários projetados para 2013 e 2014 suas posições foram melhores, ou seja, a arrecadação não impacta de forma acentuada no desenvolvimento dos municípios. Resultado semelhante ao encontrado por Moratta (2015) que evidenciou que os repasses de recursos intragovernamentais não impactam no desenvolvimento econômico, dos municípios com até 10.000 habitantes de Santa Catarina. Dessa forma é possível responder que há impacto dos repasses Estaduais e Federais no desenvolvimento dos municípios, porém, devem ser somados a este a qualidade da gestão para ampliar o desenvolvimento municipal.

Enfim o trabalho teve suas limitações, pois conforme descrito o IFDM é um indicador que é apurado pela FIRJAN, que avalia as informações em saúde, educação e geração de emprego e renda. O IFDM se utiliza de dados obtidos após a divulgação pelos órgãos competentes, a metodologia do cálculo do indicador não poderia ser controlada pelos pesquisadores o que pode limitar o poder de análise dos resultados. Principalmente em análise mais detalhadas de cada 
município estudado, em destaque àqueles que apresentaram situações conflitantes entre a receita e o indicador. Uma análise mais aprofundada destes municípios pode, talvez, esclarecer meIhor o porquê da obtenção de sucesso ou fracasso no Indicador de desenvolvimento municipal. Desta forma espera-se ter contribuído com a discussão do tema e que o presente estudo sirva de motivação a novas pesquisas, de forma a ampliar a análise pormenorizada dos fatores que levam ao desenvolvimento dos municípios brasileiros.

\section{REFERÊNCIAS}

ABRUCIO, F. L. O impacto do modelo gerencial na administração pública: um breve estudo sobre a experiência internacional recente. Cadernos ENAP, n. 10. Brasília: ENAP, 1997.

ANDRADE, Maria Margarida de. Introdução à metodologia do trabalho científico: elaboração de trabalhos na graduação. São Paulo: Atlas, 2002.

BOVAIRD, T.; LÖFFLER, E. Public management and governance. London: Routledge. 2003.

BRESSER-PEREIRA, L. C. A reforma do Estado brasileiro e o desenvolvimento. Revista eletrônica sobre Reforma do Estado, n. 3, set./ nov., 2005.

BRESSER-PEREIRA, L. C. Gestão do setor público: estratégia e estrutura para um novo estado. In: BRESSER PEREIRA, L. C.; SPINK, P. (Org). Reforma do Estado e administração pública gerencial. Rio de Janeiro: FGV, 2006.

BRESSER-PEREIRA, L. C. Reforma gerencial de 1995. Revista do Serviço Público, Brasilia, 1996. Disponível em:<http://www. reformadagestaopublica.org.br/>. Acesso em: 06/06/2012.

CARDOSO JR., J. C. Planejamento governamental e gestão pública no Brasil: elementos para ressignificar o debate e capacitar o Estado. Brasília: Ipea, 2010.

COUTINHO, R. S. Os impactos dos royalties petrolíferos sobre 0 desenvolvimento econômico local: um estudo comparativo entre os municípios de Campos dos Goytacazes e Niterói. Dissertação (Mestrado)-Programa de Pós-Graduação em Ciência Política, Universidade Federal do Rio Grande do Sul, Porto Alegre, 2008.

CUNHA, J. V. A. da; COELHO, A. C. Regressão Múltipla. In: CORRAR, L. J.; PAULO, E.; DIAS FILHO, J. M. (Org.) Análise Multivariada: para Cursos de Administração, Ciências Contábeis e Economia. São Paulo: Atlas, 2007.

FARAH, M. F. S. Administração pública e políticas públicas. Revista de Administração Pública, v. 45, n. 3, p. 813-36, 2011.

FECAM, Federação Catarinense de Municípios. Portal das Transferências Constitucionais - SC de 2012. Disponível em: http://receitas.fecam. org.br/estado. Acesso em 25 de junho de 2013.

FIESC, Federação das Indústrias do Estado de Santa Catarina. Santa Catarina em Dados: 2014/ Unidade de Política Econômica e Industrial. Florianópolis: FIESC, v. 24. p. 1-192. 2014.

FIATES, G. G. S. Modelos de gestão e gestão pública. Palhoça: Unisul Virtual, 2007

FIRJAN, Federação da Industria do Rio de Janeiro. Índice FIRJAN de Desenvolvimento Municipal - IFDM. 2013. Disponível em: http://www.firjan.com.br/ifdm/ Acesso em: 10 agosto 2013.

FRANÇA FILHO, G. Definindo gestão social. In: Silva J. et al. (Orgs.). Gestão social: práticas em debate, teorias em construção. Fortaleza: Imprensa Universitária, 2008.

HARMON, M. M.; MAYER, R. T. Teoría de la 
organización para la administración pública. México: Fondo de Cultura Econômica, 1999.

MAROCO, J. Análise estatística com utilização do SPSS. 3. ed, Lisboa: Sílabo, 2007.

MATIAS-PEREIRA, J. Administração pública comparada: uma avaliação das reformas administrativas do Brasil, EUA e União Europeia. Revista de Administração Pública, v. 42, n. 1, p. 61-82, jan./fev., 2008.

MATOS FILHO, J.; SILVA, M. J. A. da. O gasto público nos municípios produtores de petróleo no estado do Rio Grande do Norte: uma avaliação dos efeitos dos royalties sobre o desempenho das finanças e das políticas públicas. In: ENCONTRO DA ASSOCIAÇÃO NACIONAL DE PÓS-GRADUAÇÃO E PESQUISA EM ADMINISTRAÇÃO, 32., 2008, Rio de Janeiro. Anais.... São Paulo: ANPAD, 2008.

MÁXIMO, W. Governo reduz previsão de receita para 2015. 2015. Disponível em: http://agenciabrasil.ebc.com.br/economia/ noticia/2015-09/governo-reduz-previsaode-receita-para-2015-mas-nao-corta-novosgastos Acesso em: 25 out. 2015.

MEIRELLES, H. L. Direito administrativo brasileiro. São Paulo: Revista dos Tribunais, 1984.

MEIRELLES, H. L. Direito municipal brasileiro. São Paulo: Malheiros Editores, 1997.

MENDES, M. Federalismo fiscal. In: Biderman, C.; Arvate, P. (Org.) Economia do setor público no Brasil. Rio de Janeiro: Elsevier, 2004.

MORATTA, Nelson Granados. A participação das transferências intergovernamentais no crescimento econômico dos municípios: um estudo no estado de Santa Catarina. 2015. 155 f. Dissertação (Mestrado em Planejamento e Governança Pública) - Universidade Tecnológica Federal do Paraná, Curitiba, 2015.

MOREIRA, J.M.; ALVES, A.A. Gestão Pública: entre a visão clássica da Administração
Pública e o novo paradigma da Governação Pública. Revista Enfoques: Ciência Política y Administración Pública, v. 7, n. 11, p. 11-36, 2009.

MOTTA, P.R. A modernização da administração pública brasileira nos últimos 40 anos. Revista de Administração Pública, v. 41, n. esp., p. 87 96, 2007.

OATES, W. E. An Essay on Fiscal Federalism. Journal of Economic Literature, v. 37. n. 3. p. 1120-1149. sep. 1999.

PACHECO, C. A. G. A aplicação e os impactos dos royalties do petróleo no desenvolvimento econômico dos municípios confrontantes da Bacia de Campos. Monografia (Instituto de Economia), Universidade Federal do Rio de Janeiro, Rio de Janeiro, 2003.

RAUPP, Fabiano Maury. BEUREN, Ilse Maria. Caracterização da Pesquisa em Contabilidade. In. BEUREN, Ilse Maria (Org). Como elaborar trabalhos monográficos em contabilidade: teoria e prática. 3. ed. São Paulo: Atlas, 2008.

ROSA, M. F. E. Direito administrativo. 2. ed. São Paulo: Saraiva, 2001.

SANTA CATARINA. Mensagem Anual à Assembleia Legislativa. Governo do Estado de Santa Catarina. Florianópolis, 2012.

SANTA CATARINA. Arrecadação do Estado fecha trimestre com crescimento acumulado de 4,23\%. 2015. Disponível em: http://www.sef.sc.gov.br/noticias/ arrecada\%C3\%A7\%C3\%A3o-do-estado-fechatrimestre-com-crescimento-acumuladode-423 Acesso em: 22 de outubro 2015.

TIEBOUT, C. M. A pure theory of local expenditures. The Journal of Political Economy, v. 64, n. 5, p. 416-424, oct. 1956.

TORRES, W. C. Desigualdades econômicas interregionais, capacidade tributária e esforço fiscal dos estados e renda per capita 1995 a 2012. Economia política do desenvolvimento 
Maceió, v.6, n.17, p. 31-64, maio/ago. 2013.

WALDO, D. 0 estudo da administração pública.

2. ed. Rio de Janeiro: FGV, 1971.

ZAPELINI, M. B.As "big questions" da administração pública: uma proposta para o caso brasileiro. Gestão e Sociedade, v. 5, n. 11, p. 155-175, maio/ago. 2011.

ZMITROWICZ, W., BISCARO, C., MARINS, K. R. C. C. A organização administrativa do município e o orçamento municipal. São Paulo: EPUSP, 2013. 38 p. (Texto Técnico da Escola Politécnica da USP, Departamento de Engenharia de Construção Civil, TT/PCC/20). 